\title{
Data Driven Information Flow in E-Universities: A Process Modeling Analysis
}

\author{
Rasha Ismail and Atik Kulakli
}

\begin{abstract}
Advancements in information and communication have a big impact on people's life. The quality of information affects the decisions made by the management. This paper focusses on the analysis of data flow in the of 'Handling a lecture' process at two universities. Based on the process analysis, the demonstration of the activities, roles and data flow enabled the authors to compare the flow of data in the two processes. This analysis aids in evaluating the quality of data and the means of improvements to obtain well-structured data for better analysis and decision making. The impact of improvement will need to be reflected again in the process model, which indicates a triangulation between both techniques and thus each one reinforces the other. Accordingly, such methodology could be generalized and used in other universities that are aiming to make the transition to e-learning.
\end{abstract}

Index Terms-E-University, lesson planning, virtual learning, e-learning, information flow, knowledge sharing, process modeling.

\section{INTRODUCTION}

Universities, have long been accepted as major social and cultural institutions that serve developments in various forms as knowledge based organizations [1], [2]. Two common forms of universities are traditional campus base form, or electronic form such as online, distance, virtual and e-learning [3]. With the advancement of technology and communication, information can be easily collected and integrated. Information analytics is based on high qualityintegrated information. Students reach those rich content with few clicks to acquire, process and disseminate through social media tools to their friends and peers.

New skills such as computer literacy, knowledge creating, sharing, co-operative working, open source movement, collaborative working have become very important issues for academia. In the speed of information age, new generation students require new forms of learning platforms and communication channels while they already use similar applications in their private life. New forms of educational approaches needs to be more students oriented, collaborative and interactive [4]. In this context, Tapscott and Williams [5] suggest collaborative classrooms, note taking, lecturing, listening may not disappear but live alongside the new and innovative educational processes. Wissema [6] indicates that the new university concept has more industry-style

Manuscript received July 15, 2018; revised October 12, 2018. This work was supported in part by the American University of the Middle East. Data Driven Information Flow in E-Universities: A Process Modeling Analysis.

Rasha Ismail and Atik Kulakli are with American University of the Middle East, Egaila, 15453 Kuwait (e-mail: rashafa@gmail.com, atik.kulakli@aum.edu.kw). collaborative framework rather than old classroom school model. Innovation, interaction, collaboration are key

elements along with technology-driven initiatives. Similarly Tapscott and Williams [7] concentrates on usergenerated media, social networking, crowdsource effect and peer production for the new university concept which mass collaboration is a new form of online collectivism. This paper will present a review of the literature with regards to the evolution of e-university including data flow in the of 'Handling a lecture' process at two universities.

\section{LITERATURE REVIEW}

In the literature, university and educational forms have been categorized as online learning including distance (online) learning/education, virtual universities, virtual learning environments, e-learning, mobile learning, social networking and Web 2.0 based education. Some other definitions of virtual teaching and learning found as Learning 2.0; university 2.0; pedagogy 2.0; and library 2.0 [8]-[10]. From this point, we prefer to use virtual university as an educational institution to be considered an e-university it needs to delivery every aspect of university online including teaching, processes, structures, working place, staffing, administration, support, aid, assessments, evaluations, and services [11]. These requirements include technology and changing expectations, content creation and distribution, accessibility, face-to-face on campuses, open access sources, ethics, legal and social issues, privacy, learning skills, motivation, curriculum-administrative needs, system management, and communication with peers [10], [12]-[14].

\section{A. E-University Context}

Online learning provides enormous sources to access the content and enrich sharing among peers. It provides revolutionizing access to reach mass population with rich and various content availability which has been designed to complement rather than compete with old school learning. This new shape of education forces educational organizations to adapt themselves and compete in highly demanding educational area. Students are demanding more access to sources while organizations try to prepare more competitive learning packages for them. Mazoue [8] suggest that the emergence of learning sciences, the wikification of knowledge, the unbundling of faculty roles, and the migration of learning online are driving fundamental institutional change toward location-independent alternatives. Therefore, Internet is becoming the dominant infrastructure for knowledge exchange among people and new generations of students [5]. Another element discussed in success of e-university is the appropriate use of 
technology. Some of the universities have experimented euniversity concept in the virtual environment with some successes [15], [16].

For the full concept of E-universities to be realized, strategies have to be in place that exploits under-utilized capacities of technologies to improve student engagement, motivation, and higher order thinking skills [17], [18]. There have been several technological advances that are set to guide new opportunities for the raise of e-university. Researchers have predicted that Internet of Things (IoT), virtual reality, augmented reality, quantum computing, artificial intelligence, and simulated intelligence are set to transform educational delivery and resurrect the idea of a fully integrated e-university [19] along with some improvements include faster video streaming, virtual reality [20], teaching experiments improvements [21], and augmented reality simulation games in education [22]. There are some considerable advantage in using technology to automate educational teaching. Having new teaching and learning technologies can reduce costs and may increase quality simultaneously. Many high ranked universities such as MIT, Harvard, Stanford, University of Michigan, and University of Pennsylvania are delivering online free courses [23]. Students would be more flexible to choose their preferred courses, at their own pace, accessibility independent of location as well as having better value for money [24], [19].

\section{B. Existing Online University Models}

There has been attempts to design and re-model aspects of online learning. The model of Global Network for Higher Learning focuses on knowledge created and shared in teaching and learning processes of a university by suggesting open content and the emerging global metauniversity as a model. In this model there are five stages which are course content exchange, course content collaboration, course content co-innovation, knowledge cocreation, and collaborative learning connection [5].

Another example is that of Massive Open Online Courses (MOOCs), which aims to reach millions of learners around the world. MOOC refers to an online course that is free and open for anyone with particular curriculum that content over an internet connection [25]. Example of MOOCs are Coursera, edX (Harvard, MIT) and Udacity [26].

In all these cases, the models represents important pace towards e-university but failed to complement the full process aspects of a physical university in the conventional way. They represent variations that can contribute to the process and specifically the process model for universities moving from physical and virtual. Prerecorded lessons and content uploading fail to account to the real experience students get from the physical university and ability of instructors to apply different pedagogical approaches to teaching. To truly appreciate the gap, there needs to be a comparison between physical and virtual classroom interactions. There has been several works done with regards to physical university process modelling including automation of key processes. Tapscott and Williams [5] also argue that the new shape of university has to have two important characteristics such as 'collaborative learning' and 'collaborative knowledge production' both traditionally linked to classroom operations.

\section{Information Flow in e-Learning and e-Universities}

Online platforms bring rapid changes in information flow even more accessible to everyone with educational tools, online sources, and systems used in the organization. On the other hand, reliability of content is a very important issue today; because there are lots of information and knowledge sharing interactions could be found across all channels and those would not be filtered properly.

Time is limited for the educational process, so that online educational tools encourage scholars to follow better designed in-class activities along with curriculum needs in order to enable successful practices. Besides location boundaries would be eliminated with online platforms to reach greater participants at the same time. Once educators build an active network with learners in same interests can start interacting and sharing immediately. One-to-many or many-to-many form of communication brings flexibility and more effective information flow about peer activities [3].

Blacburn [27] studied on how the technology can play a key role in student learning and educators can adopt innovative technology based approaches. According to findings of online problem-based learning (PBL) resources allows students to interact authentic, complex and realistic problem designed in that environment which enhances student learning outcomes. Educational technology rapidly changes more interactive forms from traditional textbook learning to online resource oriented. [28], [29]. Technology driven educational platforms (e-learning) are increasingly being used by educators who wish to adopt their curricula with innovative teaching-learning. Due to change of traditional one-way communication between faculty and students to more contemporary method of student-centered multiple way of communication enhances learning activities to acquire new form of information flow and knowledge sharing [30], [27]. Student outcomes would be improved by using e-learning technologies in learning initiatives, thinking and problem solving skills and communication among peers [31]. Although those technologies (namely educational software and hardware) costly for any institution to apply but there are considerable benefits of using them in scalability, richer functionality and more features, content availability and capability for content development and sharing proper information in various forms.

E-university model has been increasing with e-learning initiatives along with pervasive learning technologies and approaches. E-learning projects as strategic objectives for higher educational institutions have provided enormous benefits them in content creation, managing sources, motivating learners, innovative classroom settings, scenariobased learning and problem solving skills as well as key components of digital age activities supported by web technologies [32]. Available educational technology also enables greater accessibility to information, effective content delivery, personalized learning initiatives, standardization of processes, on-demand content sharing, web-based course homepage system, multimedia integrated learning, [33], [34].

Dee and Leistyle [4] studied on knowledge sharing and flow in a large public university in USA. According to 
findings, knowledge flow has impact on quality assurance of institutional decision-making, innovative teaching practices, improve organizational performance, active-passive forms of knowledge creation in terms of cross functional team communication and disseminating teaching practices within university departments. The joint production of knowledge enables knowledge transformation across all the units. Strategic planning though organizational practices need collaborative work in order to implement new educational initiatives which supports innovative teaching practices and opportunities for professional development. Wang [35] similarly contributes that knowledge socially constructed with cognitive development [36] and information literacy has critical role for integrated curriculum creation along with planning, assessment, interactivity and information sharing. Participants included departments, librarians, campus support units, information professionals join the processes to support development programs, course content, activities, assignments and assessments in collaborative ways.

\section{Process Modelling}

Process modelling identifies processes in two different ways; an abstract model and a detailed model [37]. The purpose of modelling is to link the process design with the implementation. In the abstract model, an overall picture about the organisation's processes would be drawn. However, in the detailed model, every process could be investigated independently.

The generated model could then be used to produce a prototype for the flow of work and the flow of information; consequently, improvements could be easily managed [38]. Process modelling can be used to break an organisation's activity down into small processes made up of actions and interactions. The modelled processes can then be analysed and perhaps improved. New processes can be designed and the old ones altered. With the support of business process management software, processes in a model can be enacted to become real processes in the organisation.

\section{E. Riva Method}

The Riva method of process modelling is considered a business-oriented rather than software-oriented, in that it focuses on the management of business entities through the actions and interactions of different roles, rather than on a reduction of business to logic [39]. At this stage the paper will focus on the detailed Role Activity Diagramming (RAD) retrieved from a previous research [32] of 'Handle a lecture' Process to explore the detailed activities in this process.

Using Ould's Riva method, the educational Process model is retrieved in this paper to map the traditional educational processes onto the automated/online educational system while focusing on the data flow in each one. The retrieved diagrams is the 'Handle a Lecture' process in traditional and virtual universities that explains the detailed activities, roles and flow of data in each process.

At this stage the paper will focus on the difference between the two systems from the perspective of data flow. The RAD is used to explore the activities that are taking place in the same process for the two universities.

Riva technique is one of the techniques that is used to show the details of how organizations run their processes and activities in a dynamic view and on different detailed architectures. The model also could be used to be generalized on other organizations in the same line of business, which will support the study to map the traditional educational system to the virtual educational system. Perhaps we find some processes are deducted, modified or added in the current model. Changes or improvements that will be applied on a process will also be reflected in the improved model.

\section{MethodOLOGY}

The research aim is to analyze the data flow in both traditional and integrated e-university to design a framework for other universities in the transition to e-learning. This analysis based on the process model retrieved from a previous work [32] so that the information flow would be traced to map the differences and similarities in both systems. The analysis explores the need for process modeling before data flow analysis takes place. For this to be completed the authors agreed the methodology to follow these defined research objectives.

1- To conduct a literature review on existing models for e-university.

2- To identify gaps in the literature with regards to key process modeling.

3- To use the process model that was previously developed for both universities for the purpose of data flow analysis.

4- Validate and compare data flow in the two universities from different perspectives.

5- Make recommendations for improvements and changes.

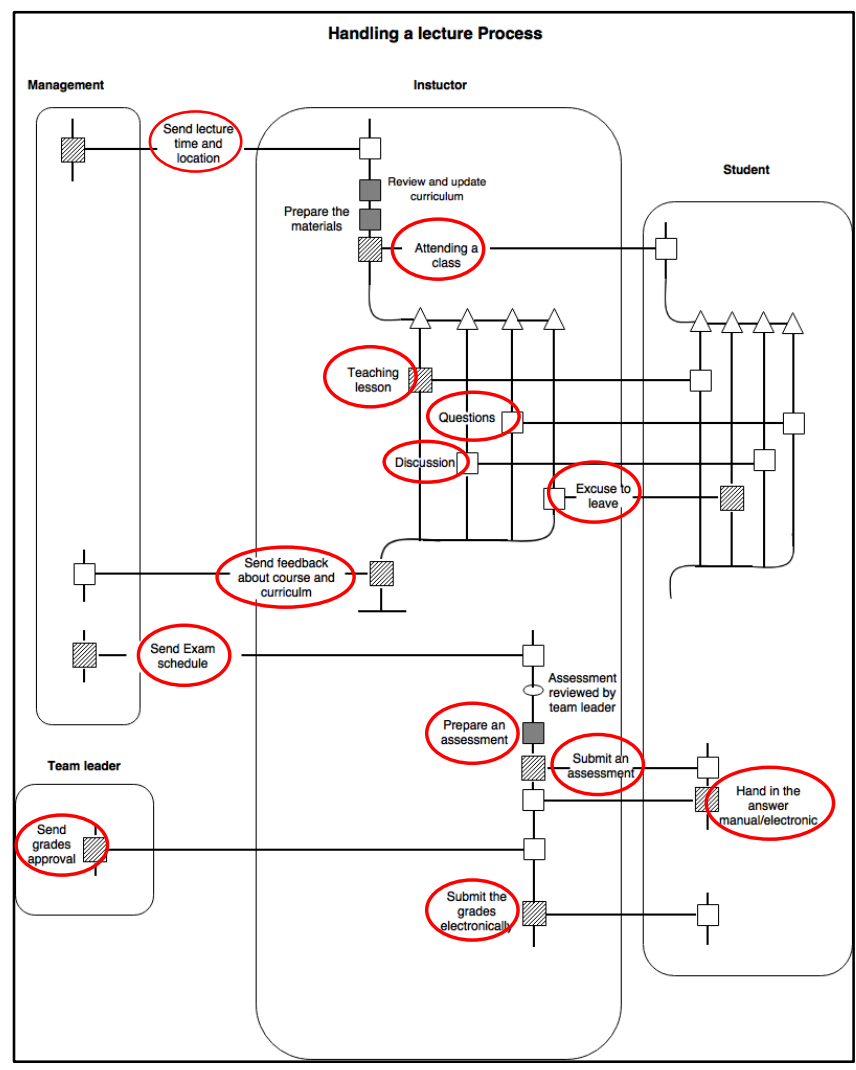

Fig. 1. Handling a lecture at the traditional system. 


\section{RESEARCH FINDINGS}

Comparing data flow in the two processes (manual and virtual) was made easy by using Role Activity Diagramming (RAD), the two models explain in details data interaction between roles and the activities from and to which they are passing. Fig. 1 and Fig. 2 are retrieved from a previous work [32] that was prepared to analyze the process for the manual and the virtual systems in details. Words in the circles refer to pieces of data that flow between roles and activities.

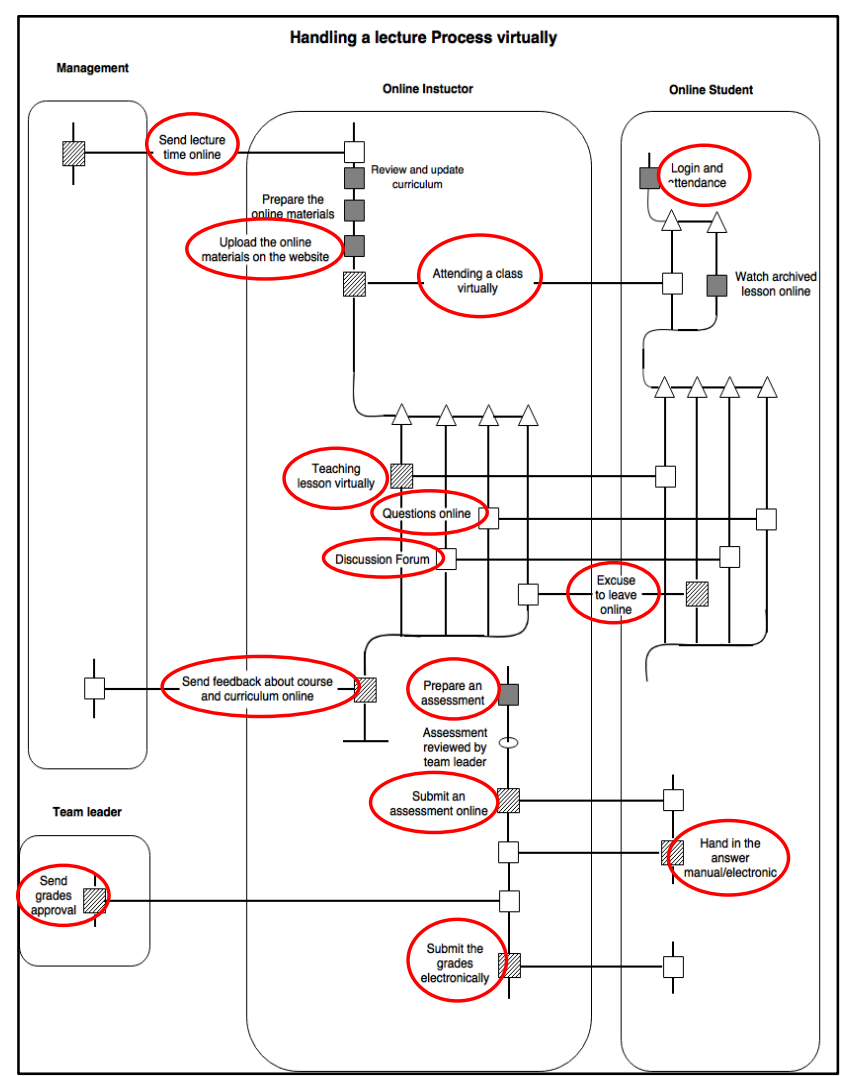

Fig. 2. Handling a lecture at the virtual system.

The following table summarizes the differences and similarities between both processes:

\begin{tabular}{|c|c|c|}
\hline $\begin{array}{l}\text { Points of } \\
\text { comparison }\end{array}$ & Manual & Virtual \\
\hline $\begin{array}{l}\text { Number of data } \\
\text { transfer }\end{array}$ & 12 & 14 \\
\hline State of data & $\begin{array}{l}\text { Written, oral, and } \\
\text { online/digital. }\end{array}$ & All online/digital. \\
\hline Location of data & $\begin{array}{l}\text { Paper, system } \\
\text { (database) or not } \\
\text { stored }\end{array}$ & $\begin{array}{l}\text { On the system } \\
\text { (database) }\end{array}$ \\
\hline $\begin{array}{l}\text { Location of } \\
\text { storage }\end{array}$ & Different locations. & Centralized location. \\
\hline $\begin{array}{l}\text { Data sharing } \\
\text { electronically }\end{array}$ & $\begin{array}{l}\text { It is possible if data } \\
\text { stored in the } \\
\text { database }\end{array}$ & $\begin{array}{l}\text { All data in the } \\
\text { database could be } \\
\text { shared according to } \\
\text { permissions. }\end{array}$ \\
\hline $\begin{array}{l}\text { Technology used } \\
\text { and systems }\end{array}$ & Moderate. & Advanced. \\
\hline Security system & $\begin{array}{l}\text { On assessments and } \\
\text { grades, for both } \\
\text { physical and online } \\
\text { data. }\end{array}$ & On all information. \\
\hline $\begin{array}{l}\text { Data quality } \\
\text { (input) }\end{array}$ & $\begin{array}{l}\text { Depends on the } \\
\text { system user. }\end{array}$ & $\begin{array}{l}\text { High quality, all } \\
\text { electronic and } \\
\text { complete data exists. }\end{array}$ \\
\hline Data quality & Depends on the & High quality all \\
\hline
\end{tabular}

\begin{tabular}{|l|l|l|}
\hline (output) & input data. & $\begin{array}{l}\text { electronic and } \\
\text { complete data exists. }\end{array}$ \\
\hline Data integration & Partly integrate. & Totally integrate. \\
\hline Data analytics & $\begin{array}{l}\text { No accurate analysis } \\
\text { because of poor data } \\
\text { quality. }\end{array}$ & $\begin{array}{l}\text { Accurate analysis } \\
\text { because of good data } \\
\text { quality. }\end{array}$ \\
\hline
\end{tabular}

Refer to Table I, it was found that the number of data flow in both processes is nearly the same. However, the structure of data differs as the mean of data usage is different. Therefore, data in the manual system can be in different states, however, in the virtual system it is all online or digital. When data needs to be stored, in the manual system there is more than one location; some data might be stored in physical files manually, some in the database otherwise not stored at all, unlike the virtual system, as all data moves electronically in digital format so all data is stored in a centralized database/s. because not all the data is stored in the database, so data in the manual system is not totally shared, only the data stored in the database, while in the virtual system data could be shared following the permissions and business rules assigned by the management. Most interactions in the traditional lecture take place physically while also the level of technology used is limited to share the schedule of lectures, take attendance, record the students' grades and publish them online to the students. Data entered in traditional lecture requires human intervention at each action to store the data in the system, however, in the virtual system the user interaction with the system yields data entry to the system. For instance, student's attendance is recorded in the systems when the student logs onto the system to attend a lecture. As a result data stored in the virtual system is more cohesive and of higher quality than in the traditional system, which impacts data analysis and decision making.

\section{DISCUSSION AND ANALYSIS}

Riva model made the process clear to understand and analyze the data flow. Ould's model provides analysis of the activities [40], data and interactions between roles within a process. As a result of this analysis, one can track the flow of data and analyze activities where improvements can take place. Poor data could be discovered and treated by automating some activities. The model shows that information that exists online can be accessed at anytime from anywhere, lectures are stored on the system, and students are also able to revisit in an e-learning format the lecture/lesson at later stage. Text analytics assists in answering questions, or inquiring about a specific topic. It is evident from this analysis that nearly all the data in both systems (traditional and online) is the same, they mainly differ in accessibility, integrity, accuracy and availability. While data is the same in both systems, more data was found in the virtual database than in the traditional database. The analysis also shows that there is no evidence that the system can verify if the student who logs onto the system is the legitimate student, however, at this stage this might not be of great importance. More technological devices exist now a days to verify the identification of a student that is considered critical in the exam process.

Analyzing data flow using Ould's model demonstrates the 
triangulation between process modeling and data flow analysis. Without process analysis one can hardly figure the flow of data within a process, the model also provides a clear view of electronic and manual data entering and coming out of the system. Every change that happens in the flow of data due to changes in the flow of work will need process modeling to represent the latest changes. Therefore, both techniques are reinforcing each other, the transition to e-learning could be generalized to other universities based on the proved analysis.

\section{CONCLUSION AND FURTHER RESEARCH}

The aim of this paper is to look at the data flow in the 'Handle a lecture' process. Evidently this analysis shows that process modeling is a precedent step to data flow analysis. This analysis might imply improvements in data flow to take place that will also inforce a change in the model to take place. This triangulation between the two methods is crucial to generalize the same method for other processes or colleges that are making the transition to elearning. The next investigation is for the 'Handle an exam' process. This investigation will provide further understanding for the needed security systems for the data transferred online. Will exams be secure if implemented online? What will be the key identification method for students? Which data is valued as confidential?

\section{REFERENCES}

[1] D. Blackman and M. Kennedy, "Knowledge management and effective university governance," Journal of Knowledge Management, vol. 13 , no. 6, pp. 547-563, 2009.

[2] A. K. Tötterman and W. W. Gunilla, "Web 2.0 and collaborative knowledge in the university context," Nuevas Perspectivas Para la Difusión y Organización del Conocimiento: Actas del Congreso Servicio de Publics, 2009.

[3] A. Kulakli and S. Mahony, "Knowledge creation and sharing with web 2.0 tools for teaching and learning roles in so-called university 2.0," Procedia-Social and Behavioral Sciences, vol. 150, pp. 648-657, 2014.

[4] J. Dee and L. Leisyte, "Knowledge sharing and organizational change in higher education," The Learning Organization, vol. 24, no. 5, pp. 355-365, 2017.

[5] D. Tapscott and A. D. Williams, "Innovating the 21st-century university: It's time!" Educause Review, vol. 45, no. 1, pp. 16-29, 2010.

[6] J. G. Wissema, Towards the Third Generation University: Managing the University in Transition, Edward Elgar Publishing, 2009.

[7] D. Tapscott and A. D. Williams, Wikinomics: How Mass Collaboration Changes Everything, Penguin, 2008.

[8] J. G. Mazoué, "The deconstructed campus," Journal of Computing in Higher Education, vol. 24, no. 2, pp. 74-95, 2012.

[9] A. Armellini and D. Hawkridge, "Utopian Universities: A technicist's dream," Journal of Computing in Higher Education, vol. 24, no. 2, pp 132-142, 2012.

[10] D. H. Wong, "Reflections on student-university interactions for next generation learning," Asia Pacific Journal of Marketing and Logistics, vol. 24, no. 2, pp. 328-342, 2012.

[11] I. Lee, Y. Im, H. Heo, and S. Chun, "Searching for academic and organizational model e-universities," in Proc. ED-MEDIA, Association for the Advancement of Computing in Education, 2003, pp. 3166-3173.

[12] T. Franklin and M. V. Harmelen, "Web 2.0 for content for learning and teaching in higher education," Teaching in Higher Education, 2009.

[13] B. Kelly, "A review of current and developing international practice in the use of social networking (web 2.0) in higher education," 2008.

[14] H. Eijkman, "Academics and Wikipedia: Reframing web 2.0+ as a disruptor of traditional academic power-knowledge arrangements," Campus-Wide Information Systems, vol. 27, no. 3, pp. 173-185, 2010.
[15] S. Warburton, "Second Life in higher education: Assessing the potential for and the barriers to deploying virtual worlds in learning and teaching," British Journal of Educational Technology, vol. 40, no. 3, pp. 414-426, 2009.

[16] H. Freeman, S. Ryan, D. Patel, T. Roudten, and B. Scott, The Virtual University: The Internet and Resource-Based Learning, Routledge, 2013.

[17] J. G. Hedberg, "E-learning futures? Speculations for a time yet to come," Studies in Continuing Education, vol. 28, no. 2, pp. 171-183, 2006.

[18] D. Laurillard, "Technology enhanced learning as a tool for pedagogical innovation," Journal of Philosophy of Education, vol. 42, no. 3-4, pp. 521-533, 2008.

[19] F. Safieddine, R. Ismail, and A. Kulakli, "E-Universities: Reflective analysis into technological trends," in Proc. the 15th International Conference on e-Society, Budapest, Hungary, 2017.

[20] H. K. Wu, S. W. Y. Lee, H. Y. Chang, and J. C. Liang, "Current status, opportunities and challenges of augmented reality in education," Computers \& Education, vol. 62, pp. 41-49, 2013.

[21] J. N. Bailenson, N. Yee, J. Blascovich, A. C. Beall, N. Lundblad, and M. Jin, "The use of immersive virtual reality in the learning sciences: Digital transformations of teachers, students, and social context," The Journal of the Learning Sciences, vol. 17, no. 1, pp. 102-141, 2008.

[22] K. Squire and E. Klopfer, "Augmented reality simulations on handheld computers," The Journal of the Learning Sciences, vol. 16, no. 3 , pp. $371-413,2007$

[23] A. Cota, K. Jayaram, and M. C. A. Laboissière, "Boosting productivity in US higher education," McKinsey Quarterly, pp. 1-8, 2011.

[24] R. Ismail, F. Safieddine, and A. Kulakli, "E-university lecture delivery model: From classroom to virtual," in Proc. International Conference on Engineering \& MIS (ICEMIS), Monastir, 2017, pp. 1-7.

[25] R. Yadav, A. Tiruwa, and P. K. Suri, "Internet based learning (IBL) in higher education: A literature review," Journal of International Education in Business, vol. 10, no. 2, pp. 102-129, 2017.

[26] A. Dua, College for All, New York, USA: McKinsey \& Company, 2013.

[27] G. Blackburn, "A university's strategic adoption process of an PBLaligned eLearning environment: an exploratory case study," Education Tech Research Dev., vol. 65, pp. 147-176, 2017.

[28] M. Li, "Using the websites in interactive-based English language learning," Academic Research International, vol. 29, no. 1, pp. 24-43, 2014.

[29] M. Sandholzer, I. Rurik, T. Deutsch, and T. Frese, "Medical students' expectations towards an implementation of a family medicine textbook as a comprehensive app in Germany," Journal of Medical Systems, vol. 38, no. 10, pp. 1-9, 2014.

[30] J. R. Savery, "Overview of problem-based learning: Definitions and distinctions," Essential Readings in Problem-Based Learning: Exploring and Extending the Legacy of Howard S. Barrows, vol. 9, pp. 5-15, 2015.

[31] R. Tarmiza, M. Tarmizib, N. Lojinina, and M. Mokhtara, "Problembased learning: Engaging students in acquisition of mathematical competency," Procedia Social and Behavioral Sciences, vol. 2, no. 2 , pp. 4683-4688, 2010.

[32] P. Bacsich, "Lessons to be learned from the failure of the UK eUniversity," in Proc. the Open and Distance Learning Association of Australia Conf., Adelaide, 2005.

[33] W. Bhuasiri, O. Xaymoungkhoun, H. Zo, J. J. Rho, and A. P. Ciganek, "Critical success factors for e-learning in developing countries: A comparative analysis between ICT experts and faculty," Computers \& Education, vol. 58, no. 2, pp. 843-855, 2012.

[34] D. Findik-Coskuncay, N. Alkis, and S. Ozkan-Yildirim, "A structural model for students' adoption of learning management systems: An empirical investigation in the higher education context," Educational Technology \& Society, vol. 21, no. 2, pp. 13-27, 2018.

[35] L. Wang, "An information literacy integration model and its application in higher education," Reference Services Review, vol. 39 , no. 4, pp.703-720, 2011.

[36] I. Shubina and A. Kulakli, "From creative abilities to creative personality: contemporary debates," III. Int. Scientific-Practical Conference "Economics, Finance and Management in the 21. Century: Analysis of Trends and Development Prospects", Kiev, Ukraine, 2018.

[37] I. Beeson, S. Green, and R. Kamm, "Process architectures in higher education," in Proc. Academy for Information Systems Conference, AISeL, 2009.

[38] R. F. Ismail and I. Beeson, "Drawing out the essential business of ports," IBIMA Business Review, 2010.

[39] M. A. Ould, Business Process Management: A rigorous approach, BCS, The Chartered Institute, 2005. 
[40] R. F. Ismail and R. Abd El Aziz, "Using ICT to improve the Egyptian higher education business processes: A case study," Journal of Organisational Studies and Innovation, vol. 2, no. 3, pp. 25-38, 2015.

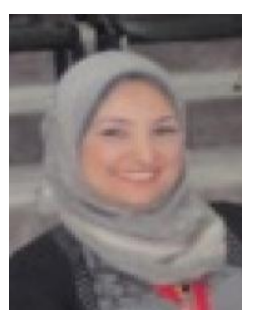

Rasha Ismail was born in Alexandria, Egypt. She graduated in 1996 from Arab Academy for Science and Technology and Maritime Transport (AASTMT) in Alexandria, Egypt - Business Administration, MIS major. Rasha obtained her MBA from AASTMT, Alexandria, Egypt in 2000, MIS major. In year 2010 Rasha obtained her Ph.D from The University of the West of England, Bristol, UK, in business information technology in the area of e-business.

In year 1996 she worked as teaching assistant in AASTMT, business administration, MIS major. In year 2000 she was promoted to a lecturer in the same place of work, and then in year 2009 she was moved to the College of International Trade and Logistics, AASTMT, Alexandria, Egypt, to teach e-business and e-supply chain. In 2010 she was promoted to assistant professor in the College of International Trade and Logistics. During the period of 2010 and 2012 she worked as e-business development consultant at IncomEgypt. In 2012 she moved to American University of the Middle East, Kuwait, to work as assistant professor in the College of Business Administration, MIS major, and then she got promoted to associate professor in 2017, she is currently working at AUM. A number of publications are done by her like 1) E-University Lecture Delivery Model: From Classroom to Virtual Monastir, Tunisia, IEEE International Engineering and MIS Conference, 2017; 2) Introducing B2i2C: An Mcommerce model for SMEs Monastir, Tunisia IEEE International Engineering and MIS Conference, 2017; 3) E-Universities: Reflective Analysis into Technological Trends, Budapest, Hungary, Proceedings of the IADIS International Conference Information Systems 2017. Her research interest was always in business process modeling, the transition to e-business and process improvements required for this transition. Still her interest is in process modeling and improvement, however, she is currently focusing on the transition to e-learning and on education automation.

Dr. Rasha Ismail was awarded certificates for attending conferences and presenting papers there, she was also awarded a certificate of appreciation as a reviewer from IBIMA, in addition to certificates of appreciation from AUM for her efforts at work

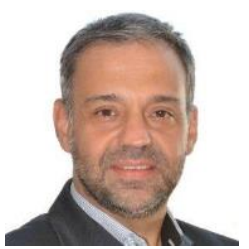

Atik Kulakli was born in Izmir, Turkey. He graduated in 1993 from Dokuz Eylul University School of Administrative Sciences and Economics, Department of Management in Izmir, Turkey. Atik obtained his MSc degree from Istanbul Technical University (ITU), School of Management Engineering in 1996 and $\mathrm{PhD}$ in the same institution in 2005. He graduated from University
College London (UCL) in 2013, he awarded MA degree in information studies (MA in electronic communication and publishing) with British Chevening full scholarship. Since graduation from ITU in 2005, he delivered courses as visiting (part-time) professor in Istanbul Commerce University, School of Engineering, Departments of Industrial Eng. and Computer Eng. both undergraduate and masters levels until 2010. He supervised numerous graduating project and master projects. Following the period he started full time academic career as assistant professor in Beykent University, School of Administrative Sciences and Economics, Department of Management, Management Information Systems and International Trade. He was assigned as vice dean between 2009 to 2011. Further he was awarded as a member of advisory committee in Provost Office in Beykent University. He was active player in planning and executing managerial responsibilities according to Dean Office requirements, curriculum development, student affair related issues, university committees such as University-Industry Cooperation Unit. During Beykent period he delivered in-class and distance e-learning undergraduate and in-class MBA programs, supervised number of graduation and master projects.

In year 2011 he started MA program in London, the UK and further worked as business consultant and delivered distance programs for Beykent University until 2014. He started American University of the Middle East (AUM), College of Business Administration, and Department of Management Information Systems, Kuwait as assistant professor in February 2014 and promoted as associate professor in November 2017 Since joining the AUM he has been delivering courses in undergraduate and MBA levels. Dr. Atik Kulakli has 17 years professional career in managing positions for industries such as Pharmaceutical, Telecommunication, Internet Service Provider, Contact and Call Center and he has consultancy experience in business management areas before academic positions.

His research interest mostly concentrated in technology management, management information systems, internet technologies, supply chain management, operations management, educational technologies (e-learning, e-university) and applications. A number of publications have been published in journals, conferences, book chapters. Most recent conference presentations and publications like "E-University Lecture Delivery Model From Classroom to Virtual Monastir, Tunisia, IEEE International Engineering and MIS Conference, 2017", "E-Universities: Reflective Analysis into technological trends, Budapest, Hungary, Proceedings of the IADIS International Conference Information Systems 2017". He has professional association memberships, conference and symposium organization committee responsibilities in editorial boards, scientific committees, and conference session chairs 